\title{
Digital Transformation Powered by Big Data Analytics: The Case of Retail Grocery Business
}

\author{
Haroon Abbu \\ VP, Data Analytics, Bell \& Howell \\ Haroon1@outlook.com
}

\author{
Pradeep Gopalakrishna \\ Pace University \\ pgopalakrishna@pace.edu
}

\begin{abstract}
Companies are investing in big data analytics capabilities as they look for ways to understand and innovate their business models by leveraging digital transformation. We explore this phenomenon from the perspective of retail grocery business where evolving consumer attitudes and behaviors, rapid technological advances, new competitive pressures, laser thin margins, and the COVID-19 pandemic have accelerated the pace of digital transformation. We specifically analyze the role of big data analytics capabilities of the top five grocery companies in the United States in light of their digital transformation initiatives. We find that retailers are making major investments in big data analytics capabilities to power all aspects of their digital ecosystem-the online shopping experience for the digital consumer, digital store operations, pickup and delivery mechanisms - to enhance shopping experience, customer loyalty, revenue, and ultimately profit.
\end{abstract}

\section{Introduction}

The topic of digital transformation has gained attention in recent years as companies try to figure out how to profitably leverage the advances in communications and computing technologies. Digital transformation is "the creation of, and consequent change in, market offerings, business processes, or models that result from the use of digital technology" [1]. It has forced companies to rethink the role and value data has in their business models [2]. However, digital transformation is much more than technology deployment. In most instances, it represents a fundamental change in the organization's underlying mindset, systems, and tools, needed to reposition parts of, or the entire, business design [3]. A focus only on selecting and implementing the right digital technologies is not likely to lead to success. Digital transformation involves leadership, talent development, culture, organization, and strategy [4].

Digital transformation is a significant change in the basic pattern of how organizations create value [5]. Data-driven companies are on average 5\% more productive and $6 \%$ more profitable than other competitors in the market. The so-called digital masters - that are characterized by visionary management and digital capabilities - are 26\% more profitable compared to their competitors [6]. Furthermore, digitally mature companies generate 9\% higher revenue from their physical assets [7].

Despite the potential to generate substantial economic benefits, very few businesses have undergone successful digital transformations. A 2017 global study of digital transformation found that only $25 \%$ of organizations had trans-formed into digital businesses, $41 \%$ were on transformative journeys, and $34 \%$ invested more time talking about the trend than they did acting on it [8]. It is noteworthy that $85 \%$ of executives stated that attaining digital maturity is critical to organizational success. The discrepancy between recognizing digitalization as a competitive necessity and successfully implementing a transformative strategy suggests that many leaders are un-sure how to harness the opportunities that a digital transformation brings to people, processes, and technology.

Big data analytics capability - the capability to acquire and analyze big data for decision making is crucial given that the functionality of digital technologies all rely on digital data [9]. Big data analytics is the use of advanced analytic techniques against very large, diverse big data sets that include structured, semi-structured and unstructured data, from different sources, and in different sizes from terabytes to zettabytes. IBM [10] defines big data as data sets whose size or type is beyond the ability of 
traditional relational databases to capture, manage and process the data with low latency. They represent high volume, high velocity and high variety data-most often driven by artificial intelligence (AI), mobile devices, social media and the Internet of Things (IoT) - where much of data is generated in real-time, at a very large scale from sensors, connected devices, video, audio, web and social media. Data processing at scale to enable real time decision making requires advanced data technologies - a key component of successful digital transformation initiatives.

\section{The Rise of Digital Grocery}

E-commerce has altered customer shopping behaviors and transformed the retail land-scapeprimarily for the non-perishable general merchandise category-from brick and mortar to omnichannel. However, grocery businesses have remained largely immune to digital disruption - until recently. Online competitors, most notably Amazon, have been able to increase product assortment, invest in advanced data analytics to personalize the shopping experience, and achieve massive economies of scale that lower cost, increase profitability, and offer lower prices to end consumers. Brick-and-mortar Grocers have started to embrace expensive investments in digitalization and automation in response to changing consumer preferences and to remain profitable. The trend only accelerated with the COVID-19 pandemic as it triggered a sudden change in customer behavior resulting in a large influx of new online orders requiring grocery businesses to deploy new procedures and new technology.

\section{The Role of Big Data Analytics in Digital Grocery Ecosystem}

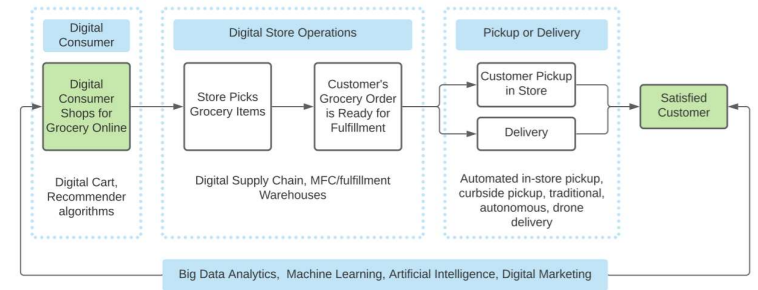

Fig 1. Conceptual Model of Digital Grocery Ecosystem

As shown in Fig 1, digital grocery ecosystem [11] consists of digital consumer (online shopping), digital store operations, and last mile pickup or delivery operations. They are interconnected and powered by big data analytics technologies. Digital Consumer is at the center of the grocery universe and the primary result of transforming to a digital business is the ability to engage and delight the shopper to drive loyalty, revenue, and profit. A key component of customer satisfaction is a seamless, user-friendly mobile shopping app that provides accurate online ordering across all categories, the ability to save and reuse shopping lists, and schedule deliveries in advance. Real-time inventory availability is critical to ensure that customers are informed in advance when their favorite items are out of stock and would allow customers to set their expectations for delivery accordingly. Digital Store Operations encompass technology and infrastructure necessary for the efficient processing of digital consumers' online grocery orders, identify the appropriate inventory necessary to support customer demand, and make realtime decisions that will focus on the outcomes. All major grocers are innovating in this space-from local fulfillment centers and dark stores to large centralized fully automated warehouses. Last Mile Pickup or Delivery is another key component of the digital grocery where customers often demand faster, same day, or even instant, delivery. This has spurred innovation in new technologies such as automated grocery pickup, curbside pickup, third party delivery services, and even drones and autonomous vehicles. Automated grocery pickup in-store allows consumers to place grocery orders online and pickup from an automated, temperature-controlled, kiosk at the store. Curbside pickup lets store employees place groceries in a customer's trunk, thereby avoiding face-to-face interaction with the customer.

Grocers are deploying sophisticated data analytics, including machine learning, artificial intelligence and digital marketing technologies to connect the components of the Digital Grocery Ecosystem to provide a seamless shopping experience. Machine learning, artificial intelligence, and digital tools are gaining in adoption including automated chat for customer support, machine-learning algorithms to predict customer arrival for a smoother experience, augmented reality and digital twin technologies to approximate the in-store experience, digital billboards to explain the nutritional content, electronic shelf labels for dynamic pricing, and machine vision to identify and remedy issues at self-service checkout. Using customer intelligence, marketers are creating relevant messages, product recommendations, and product information.

\section{Examples: Big Data Analytics in Action}


Next, we discuss our findings on digital transformation initiatives of top 5 grocery businesses (Walmart, Kroger, Albertsons, Target, Amazon Whole Foods) and the role of big data analytics.

Walmart. Walmart's Intelligent Research Lab (IRI) is designed to test real-world applications of $\mathrm{AI}$ in a fully functional Walmart that spans 50,000 square feet and sells more than 30,000 items. Through cameras, sensors and predictive analytics that estimate demand, Walmart's goal is to automate much of the restocking process. Artificial intelligence is also used to notify employees when new checkout lines grow too long and if additional registers need to be opened, as well as when the supply of shopping carts runs low.

Kroger. Kroger has been testing a smart shopping cart that can weigh items, provide shopping suggestions, and scan and pay for orders without requiring shoppers to visit a traditional checkout lanes. Kroger's smart cart—using a multitude of computer vision, sensing technologies, and AI algorithms - aims to provide an interactive dashboard-like screen that can deliver shopping list recommendations, promotional offers, wayfinding capabilities, reader for scanning loyalty app, and a credit-card payment processor enabling checkout. Kroger and Microsoft are collaborating to pilot a connected store experience-by using Microsoft Azure and AI-to introduce shopping experiences through a shelving system called EDGE (Enhanced Display for Grocery Environment) that uses digital displays to indicate prices, promotions, nutritional, dietary, and other information. Kroger plans to roll out Visual AI technology to its stores to detect and reduce customer errors at self-checkout stations. Kroger's data analytics solution leverages data captured from brick-and-mortar and digital transactions to enable brands to better position their products with consumers both in-store and online.

Albertsons. Albertsons and Microsoft are working together to leverage Azure, Azure AI and other cognitive services to transform the shopping experience by improving the ways to find the products they want, reduce wait times, and anticipate out-ofstocks and misplaced products. The company is collaborating with BloomReach that uses AI-driven data to improve the online search experience and the conversion rates.

Target. Target has largely embraced a strategy of acquiring smaller AI companies and incorporating their leadership into data science teams. For instance, Target acquired Kvantum and leveraged its expertise to develop a machine learning algorithm that identified appropriate complementary goods to advertise on a product's webpage.

Amazon Whole Foods. Machine learning drives algorithms for demand forecasting, product search ranking, product and deals recommendations, merchandising placements, fraud detection, translations, and much more. Amazon Go stores use computer vision, sensor fusion, deep learning, and sensors to determine which products customers are putting in their bags, charging the customer automatically through the app.

\section{Final Word}

In this paper, we analyzed how major grocery businesses are building and utilizing big data analytics capabilities to digitally transform their businesses. Our findings underscore the role of big data capabilities in successfully implementing multiple facets of digital transformation. Digital transformation presents significant challenges and opportunities in the highly competitive, low-margin world of the grocery industry. Retailers are investing and connecting these investments to customer loyalty, and ultimately to revenue and profit. This will result in the true transformation of business models that will define what the grocery industry becomes going forward.

\section{References}

[1] S. Nambisan, K. Lyytinen, A. Majchrzak, M. Song, "Digital Innovation Management: Reinventing Innovation Management Research in a Digital World," MIS Quarterly, 2017.

[2] J. Brownlow, M. Zaki, A. Neely, F. Urmetzer, "Data-Driven Business Models: A Blueprint for Innovation," 2015.

[3] S. Gupta, "Driving Digital Strategy: A Guide to Reimagining Your Business," Harvard Business Review Press, 2018.

[4] G. Kane, D. Palmer, A. Philips, D. Kiron, N. Buckley, "Achieving Digital Maturity: Adapting Your Company to a Changing World." 2017.

[5] G. Gudergan, P. Mugge, A. Kwiatkowski, H. Abbu, T. L. Michaelis, and D. Krechting, "Patterns of Digitization-What differentiates digitally mature organizations?" IEEE International Conference on Engineering, Technology and Innovation: 2019, pp. 1-8.

[6] A. McAfee, E. Brynjolfsson, "Big Data: The Management Revolution," Harvard business review, 90, 2012. 
[7] G. Westerman, M. Tannou, D. Bonnet, P. Ferraris, A. McAfee, "The Digital Advantage: How digital leaders outperform their peers in every industry," 2012.

[8] G. Kane, "Digital Maturity, Not Digital Transformation," 2017.

[9] C. Dremel, J. Wulf, M.M. Herterich, J.C. Waizmann, W. Brenner How AUDI AG established big data analytics in its digital transformation. MIS Quarterly Executive, 16 (2) (2017), pp. 81-100.

[10] IBM, https://www.ibm.com/analytics/hadoop/big-dataanalytics

[11] Abbu H.R., Fleischmann D., Gopalakrishna P. (2021) The Digital Transformation of the Grocery BusinessDriven by Consumers, Powered by Technology, and Accelerated by the COVID-19 Pandemic. In: Rocha Á., Adeli H., Dzemyda G., Moreira F., Ramalho Correia A.M. (eds) Trends and Applications in Information Systems and Technologies. WorldCIST 2021. Advances in Intelligent Systems and Computing, vol 1367. Springer, Cham. 